\title{
A CASE OF JUVENILE RHEUMATOID ARTHRITIS WITH SCLERODACTYLIA AND CALCINOSIS
}

\author{
BY \\ PHILIP ELLMAN and F. PARKES WEBER
}

From the Rheumatism Unit, St. Stephen's Hospital, London

An unmarried woman of 28 years was admitted to the Rheumatic Unit, St. Stephen's Hospital on March 15, 1948, under the care of Dr. Philip Ellman, complaining of inability to stoop, to straighten the elbows, and to walk up high steps, and also of pain on moving the elbows, fingers, knees, and hips, all for the previous seventeen years.

At the age of 11 years she had had a painful throat and enlarged glands in the neck, with high fever. After a few weeks these symptoms all subsided.

After a symptom-free interval of a week or two, her fingers became stiff and little nodules appeared on the dorsal aspects of both metacarpi; her knees were stiff and swollen and she also had pain in both hips. In six months this second set of symptoms cleared up. Her doctor, however, making a retrospective diagnosis of rheumatic fever, ordered her complete rest for a year, and this she had, sitting in a wheel-chair, motionless, and with the elbows and knees continually immobile in $90^{\circ}$ flexion. At the end of the year these joints were fixed.

She then (when aged 12 or 13 , sixteen or fifteen years ago) was seen by Sir Frederick (then Doctor) Still, who diagnosed Still's disease and sent her to Woodhall Spa for physiotherapy. A partial recovery ensued; she could walk again and go to school.

At 14 years of age nodules appeared also on the medial aspects of both knees, and they and the former ones began to discharge.

Since then her condition has been more or less static. If anything the joints are all looser, but the nodules, which are tender, are more troublesome than before. Two years ago the left forefinger, being ankylosed and an encumbrance, was amputated.

Direct questioning reveals that her maximum weight was $6 \mathrm{st}$. $2 \mathrm{lb}$. one year ago; now she weighs $5 \mathrm{st}$. $11 \mathrm{lb}$. Her menarche was at the age of 17 , periods now lasting five or six days, with a twenty-eight day cycle. They are regular and painful. In cold weather her hands go numb and white.

Past and family histories show nothing of significance.

Present Condition

Physical examination shows a thin young woman
(Fig. 1) with a pleasant though somewhat immature personality, and with poorly developed secondary sexual characteristics.

There is apparently slight sclerodermic contraction round the mouth as well as in the hands. Calcareous nodules, some ulcerating the skin, are seen on the fingers of both hands (Fig. 2 and 3), the medial surfaces of the knees (Fig. 4), and the medial sides of the first metatarsophalangeal joints. Symmetry is a feature of these calcinosis nodules. She has a slightly funnel type of sternum. The left forefinger has been amputated. Her spine is flattened and rigid. Elbows, wrists, and hips (and to less extent the knees) show moderately severe limitation of all movements. The finger movements are also impaired.

The cardiovascular system is normal.

The respiratory system shows no abnormality save poor but symmetrical movements.

The abdomen is normal, there being no splenomegaly; and so is the nervous system. There is no enlargement of any superficial lymphatic glands.

Special investigations have shown nothing abnormal, with the important exception of $x$-ray examination, which reveals calcinosis of the hand and wrists (Fig. 5), as well as some minor widespread old rheumatoid arthritic changes; there is some osteoporosis at the elbows.

Blood chemistry shows nothing abnormal in regard to calcium, phosphorus, phosphatase, urea, and uric acid. The blood count is normal, and the erythrocyte sedimentation rate now normal. The blood Wassermann reaction is negative, and there is no achlorhydria. The urine is free from albumin and sugar and is sterile on culture.

\section{Discussion}

The case is now a typical one of slight symmetrical sclerodermia of the sclerodactylia type associated with well-marked circumscribed calcinosis nodules of fairly symmetrical distribution in the extremities (cf. Atkinson and Weber, 1938). As in most cases of sclerodactylia, symptomatic "Raynaud-like" phenomena have been noted in the hands, which, by the way, in the present case, are the sites of most 

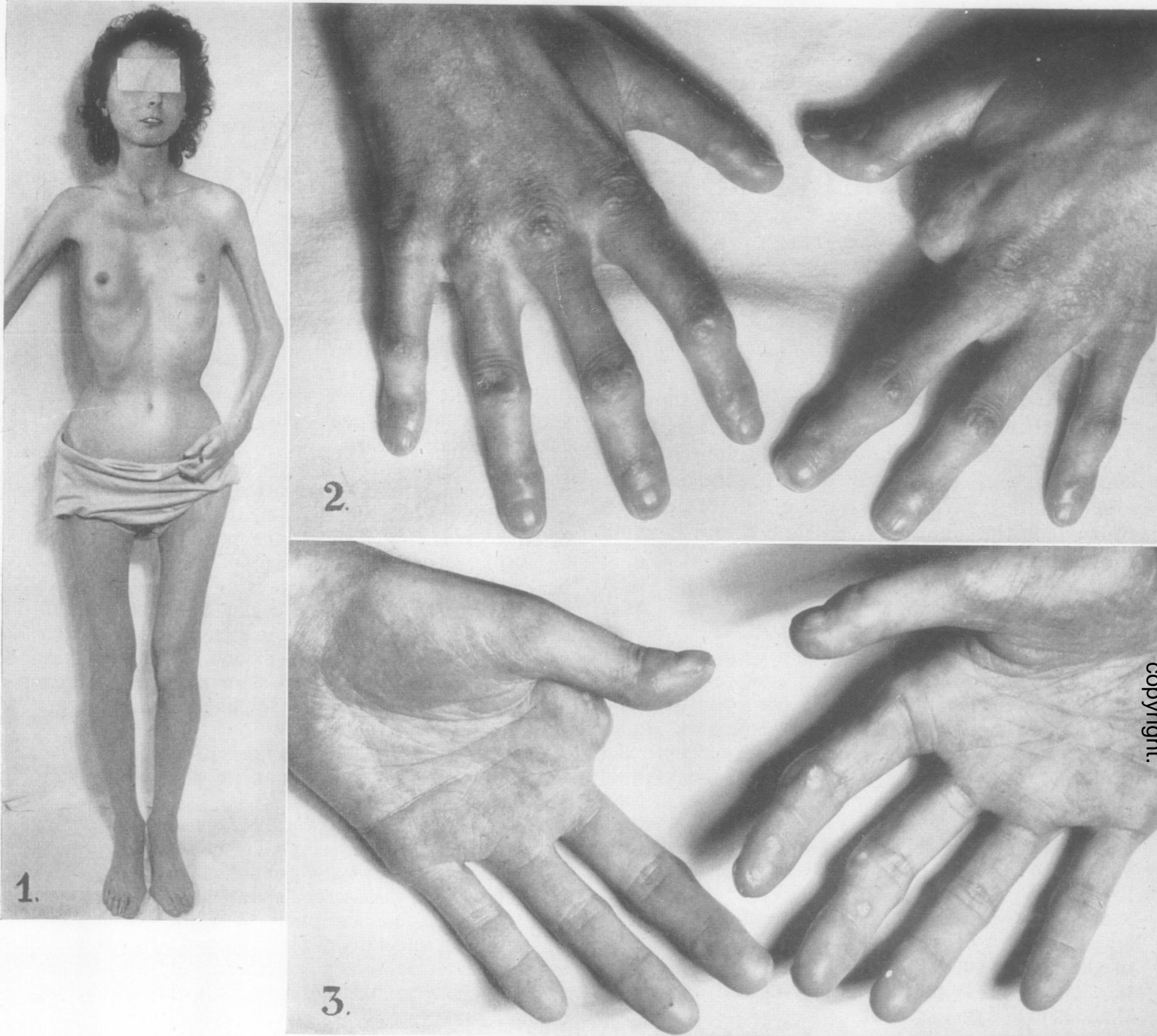

FIG. 1.- The patient in May, 1948.

FIG. 2.-Dorsal aspect of patient's hands, showing chronic remnants of juvenile rheumatoid arthritis together with early sclerodactylia and calcinosis

FIG. 3.-Palmar aspect of hands, showing calcinosis nodules.

FIG. 4.-Calcinosis nodule on inner side of right knee. (There is an exactly similar one at the corresponding position near the left knee.)

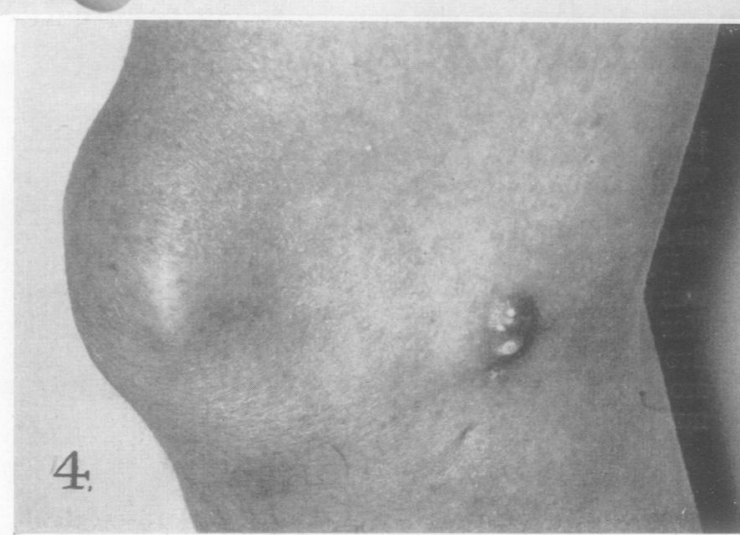




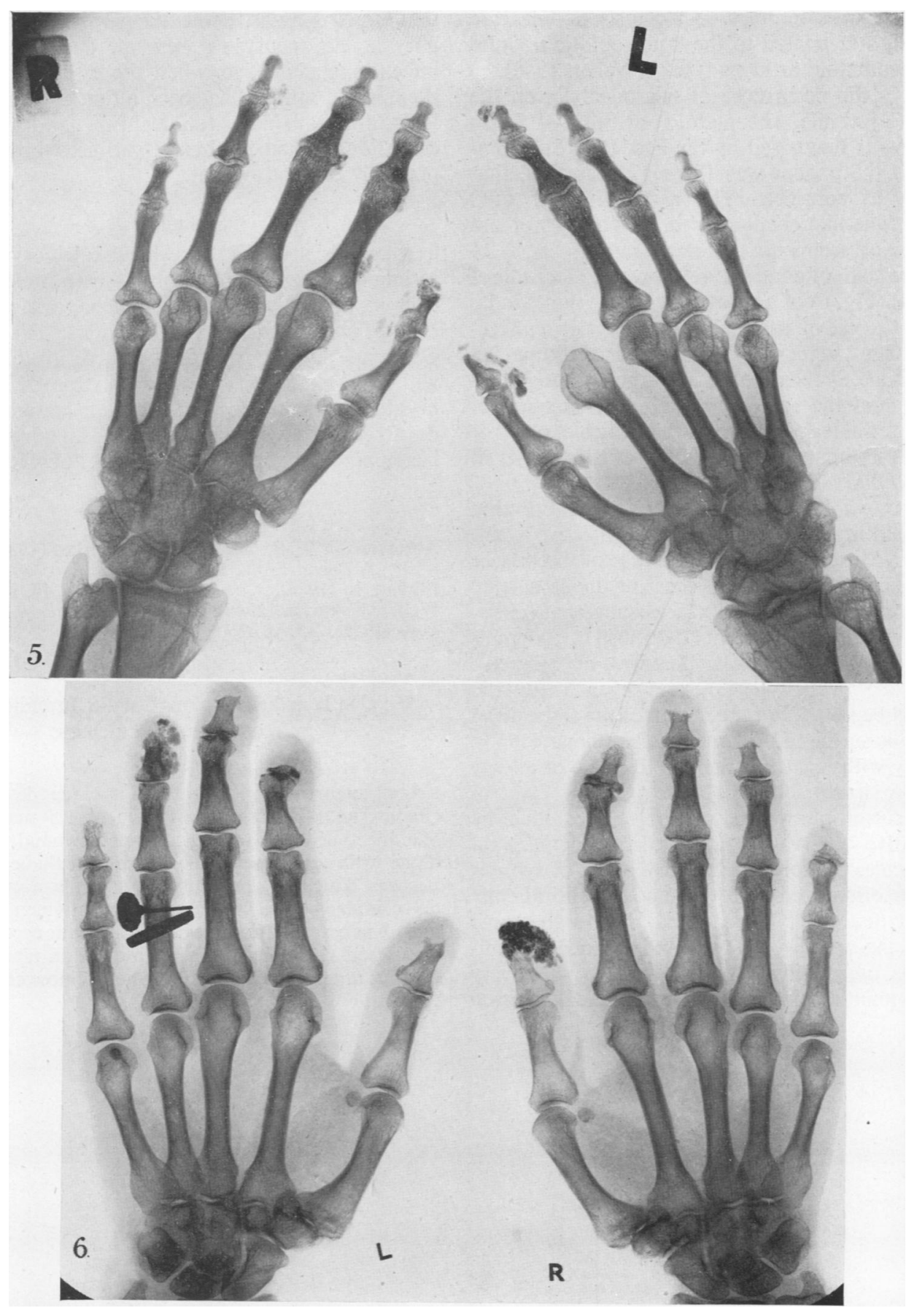

FIG. 5.-Radiograph of hands, showing calcareous deposits.

FIG. 6.-Radiograph of hands (for comparison) from a case of typical sclerodactylia with calcinosis (without rheumatoid arthritis), showing characteristic absorption of tips of the terminal phalanges. 
of the calcinosis nodules. Calcinosis nodules are apparently not related to the " necrobiotic nodules of the rheumatoid arthritis type" (Weber, 1948).

But it is the occurrence of sclerodactylia on the basis of juvenile rheumatoid arthritis-" Still's disease "- as diagnosed by Sir Frederick Still himself when the patient was 12 or 13 years old, that we wish to consider. The association of mild sclerodactylia-like changes with the changes of old Still's disease seems not extremely rare.

For the sake of contrast we show a radiograph of the hands (Fig. 6) of a woman aged 76 years, kindly referred to one of us (P. Ellman) by Dr. D. SethSmith. The calcinosis of her hands is accompanied by well-marked sclerodactylia, without rheumatoid arthritis, and the radiograph shows absorption of the tips of the terminal phalanges, which is a rather rare but very characteristic feature of some cases of sclerodactylia.

On the whole, it seems to us probable that rheumatoid arthritis is due to some infective agent, possibly a virus; but, until the cause of the disease is discovered, its relation to occasionally associated conditions, such as Raynaud's phenomena, sclerodactylia (with or without calcinosis), Sjögren`s disease (on the non-ccular features of Sjögren`s disease-see Weber, 1945), and even rheumatic fever, can be noted, but the nature of the association can be only surmised. Compare also Ellman (1947), especially with regard to the possible rôle of allergy towards a virus or other infective agent.

Such surmising would, of course, be aided by comparative observation and statistical enquiry on a large scale. Before the infective agent of syphilis had been discovered there were some who already surmised that tabes dorsalis was due to the same cause as the ordinary primary and secondary manifestations of syphilis. Just as with the discovery of the syphilitic spircchaete it was suddenly proved that tabes dorsalis, dementia paralytica, and ordinary aortic aneurysms were all due to the same infection (syphilis), so, when the essential cause of rheumatoid arthritis has been ultimately discovered, the relation of rheumatoid arthritis to various other conditions (whether already surmised or not) wi!l probably become evident.

\section{Summary}

A case is described of typical calcinosis circumscripta-mainly of the hands-with mild sclerodactylia and Raynaud's phenomena, arising on the basis of juvenile rheumatoid arthritis (Still's disease). Cases of juvenile rheumatoid arthritis associated with mild sclerodactylia are not extremely rare, but in such cases of old Still's disease combined with mild sclerodactylia typical calcinosis circumscripta has apparently been seldom; if ever, observed.

\section{REFERENCES}

Atkinson, F. R. B., and Weber, F. Parkes (1938). Brit. J. Derm. Syph., 50, 267.

Ellman, P. (1947). Proc. roy. Soc. Med., 40, 332.

Weber, F. Parkes (1945). Brit. J. Ophthalmol., 29, 299. (1948). Med. Pr., 219, 484.

\section{Un Cas D'arthrite Rhumatismale Juvenile Avec Sclerodactylie et Calcinose}

\section{RÉsumÉ}

Les auteurs décrivent un cas typique de calcinose circonscrite (affectant principalement les mains) avec sclérodactylie légère et syndrome de Raynaud, à la suite d'une arthrite rhumatismale juvénile (maladie de Still). Les cas d’arthrite rhumatismale juvénile accompagnée de sclérodactylie légère ne sont pas extrêmement rares, mais dans ces cas de maladie de Still ancienne accompagnée de sclérodactylie légère il semble que l'on n'ait observé que très rarement, sinon jamais, une calcinose circonscrite typique. 